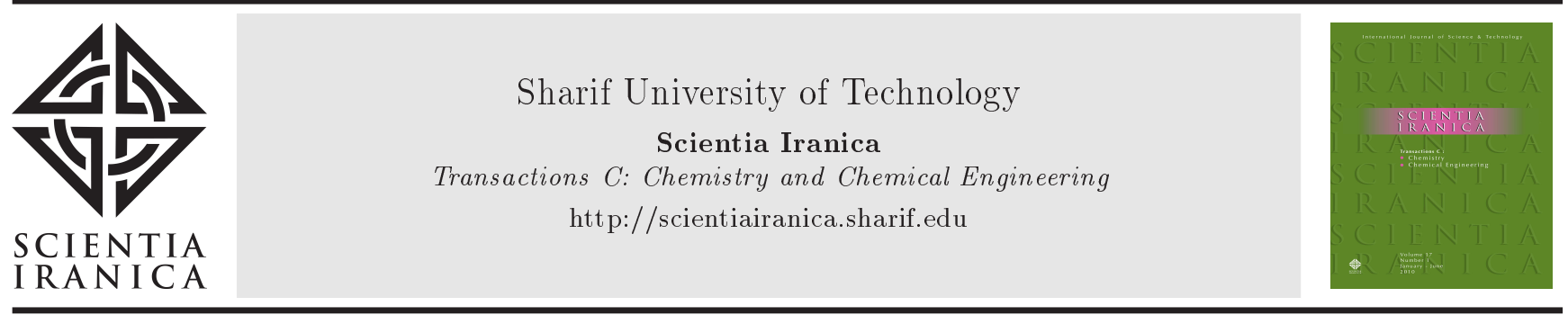

\title{
Conformation of gemcitabine: An experimental NMR and theoretical DFT study
}

\author{
S. Chashmniam and M. Tafazzoli* \\ Department of Chemistry, Sharif University of Technology, Tehran, P.O. Box 11365-9516, Iran.
}

Received 28 February 2017; received in revised form 13 June 2017; accepted 2 December 2017

\section{KEYWORDS}

Gemcitabine

(Gemzar);

NMR;

Karplus;

DFT;

Conformation;

Solvent effect.

\begin{abstract}
The structural and conformational behavior of gemcitabine $\left(2^{\prime}, 2^{\prime}\right.$-difluoro cytidine) was investigated by advanced NMR experiments and a computational quantum mechanical method (DFT) using Potential Energy Scanning (PES) in gas and solution phases in the Polarizable Continuum Model (PCM). Three stable conformers (G1, G2, and G3) were predicted from minimum points in a potential energy diagram. In order to measure coupling constant values, a set of 2D spectra (H-H COSY, H-C HMQC, and H-C HMBC) was analyzed. Optimized structures and spin-spin coupling constant calculations in gas and solution phases were performed by B3LYP/6-311++G(d,p) method. Both energy and NMR parameters showed that G1-form is more stable than other conformers are. To analyze coupling constant, Karplus equations for ${ }^{1} \mathrm{~J}_{\mathrm{C}-\mathrm{H}},{ }^{2} \mathrm{~J}_{\mathrm{C}-\mathrm{H}}$, and ${ }^{3} \mathrm{~J}_{\mathrm{C}-\mathrm{H}}$ were derived. In addition, the investigation of solvent effect was carried out, and obtained results showed that both inter- and intra-molecular interactions affected the stability of G1 conformer.
\end{abstract}

(C) 2018 Sharif University of Technology. All rights reserved.

\section{Introduction}

Nucleosides and their derivations are glycosylamines used in biotechnology and numerous biological processes [1-6]. They are also the most beneficial compounds for healing a majority of cancers [7$9]$. As a deoxycytidine analogue, gemcitabine $\left(2^{\prime}, 2^{\prime}-\right.$ difluorocytidine, $\mathrm{dFdC}$ ), Scheme 1 , is used as an effective treatment for many cancers including blood, pancreas, lung, biliary, etc. [10-16]. In recent years, a wide variety of investigations have been performed on linear synthesis of gemcitabine [17], its kinetic and diffusion studies [18], and its association with other pharmaceutical compounds to improve beneficial pharmaceutical effects $[19,20]$.

\footnotetext{
*. Corresponding author. Tel: +98 2166165305 ; Fax: +982166029516

E-mail address: Tafazzoli@sharif.edu (M. Tafazzoli).
}

Despite the fact that gemcitabine plays a key role in pharmaceutical and biotechnology fields, there is no detail found with regard to its 3D structure and stable conformers. As Scheme 1 shows, rotation around the $N$-glycosidic bond causes different conformations to the orientation of base ring rather than sugar ring. These conformers are determined by applying advanced NMR experiments along with DFT calculations [21-26]. In these methods, DFT calculations provide information about the available conformers by using the Potential Energy Scanning (PES). Then, NMR parameters, including chemical shifts and spin-spin coupling constants, are measured theoretically [27-29]. In the experimental section, structures are assigned, and values of coupling constants are obtained. To achieve this, a set of 1D- and 2D-NMR spectra is used including correlation spectroscopy (H-H COSY), Heteronuclear Multiple Quantum Coherence (HMQC), and Heteronuclear Multiple Bond Coherence (HMBC) [30-31]. Finally, these experimental and theoretical data are used to interpret 3D structure and conformational study [32-39]. 


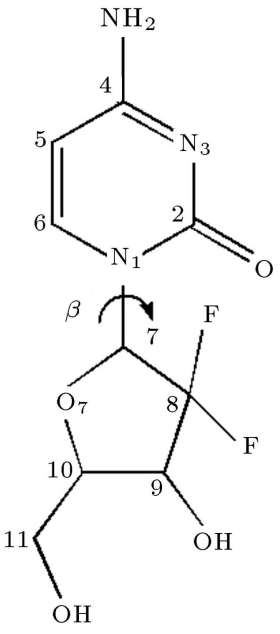

Scheme 1. Chemical structure of gemcitabine.

Coupling constant DFT studies have the best results for closely related systems, and this is the basic problem of these NMR parameters in the conformational studies [40]. In general, several parameters affect the spin-spin coupling constant. In this regard, many investigations were performed on coupling constants including bond length [41], solvent interaction [42], electronegativity of the substituent [43], etc. However, the dihedral angle dependency of coupling constant (Karplus equation) is the most important equation that considers NMR parameters in conformational studies. Accordingly, three-bond (vicinal) $\mathrm{H}-\mathrm{H}$ coupling constant is the most important one in conformational investigations [44]. In addition, one- and two-bond (geminal) spin-spin coupling constants are often considered [45].

The purpose of the current paper is to determine the spatial structure and conformations of gemcitabine by two methods: 1) one- and two-dimensional NMR experiments and 2) density Functional Theory (DFT). In addition, in this work, the ${ }^{n} \mathrm{~J}(n: 1,2,3)$ Karplus equation is obtained for gemcitabine.

\section{Experimental section}

- Material: Gemcitabine (Gemzar) was purchased from Aburaihan Pharmaceutical Co. (Tehran, Iran) and was used without further purification.

- NMR experiments: ${ }^{1} \mathrm{H}$ and ${ }^{13} \mathrm{CNMR}$ spectra were recorded with a Bruker DRX 500 operating at 500.13 and $125.77 \mathrm{MHz}$ for ${ }^{1} \mathrm{H}$ and ${ }^{13} \mathrm{C}$, respectively.

The spectra were taken in $\mathrm{D}_{2} \mathrm{O}$ solutions with a probe temperature at $298.0 \mathrm{~K}$ and referenced to solvent peak. The sample $(8 \mathrm{mg})$ was dissolved in $\mathrm{D}_{2} \mathrm{O}(0.5 \mathrm{~mL})$, and $1 \mathrm{D}$ - and 2D-NMR experiments were performed by NQR technology and BBI probe, respectively.
NMR experiments were running at $90^{\circ}(10.5 \mathrm{~ms})$, 128 transients, and $32 \mathrm{k}$ data points for ${ }^{1} \mathrm{H}$ spectra and at $90^{\circ}(15 \mathrm{~ms}), 512$ transients, and $128 \mathrm{k}$ data points for ${ }^{13} \mathrm{C}$ spectra. ${ }^{1} \mathrm{H}^{-1} \mathrm{H}$ homonuclear correlation spectroscopy (COSY) spectra were collected using cosygs pulse sequence with the following parameters: $90^{\circ}$ pulse values with 1024 increments of $1 \mathrm{k}$ data points for $12 \mathrm{ppm}$ spectral width (f1 and f2) and 64 scans. The other 2D NMR spectra were acquired with $130 \mathrm{ppm}$ (f1) and $12 \mathrm{ppm}$ (f2) spectral width, relaxation delay, $2 \mathrm{~s}, 512$ increments of $1 \mathrm{k}$ and 64 scans for ${ }^{1} \mathrm{H}-13{ }^{13} \mathrm{C}$ Heteronuclear Multiple Quantum Coherence (HMQC). The chemical shifts were referenced to the methyl groups of a TMS internal standard $(0.00 \mathrm{ppm}$ for ${ }^{1} \mathrm{H}$ and ${ }^{13} \mathrm{C}$ ).

All NMR spectra were analyzed using a professional software product, i.e. MesReNova 10.0.1.

\section{Quantum chemical calculations}

All the minimizations and calculations were carried out using the GAUSSIAN09 [46] program with the Density Functional Theory (DFT) by exchange-correlation hybrid functional B3LYP (three-parameter exchange functional of Becke B3 combined with the Lee-YangParr correlation functional LYP) approach to polarization, diffuse functions, and $6-311++\mathrm{G}(\mathrm{d}, \mathrm{p})$ basis set [47-48]. The results were analyzed with Gaussview 5.0 visualization program.

This quantum chemical method and basis set often have a correct prediction geometry and structure parameters of medium-sized molecules [49]. Molecular geometries were optimized without any restriction. Chemical shifts were calculated with GIAO method, using corresponding TMS shielding calculated at the same theoretical levels as in the reference. The relative ${ }^{1} \mathrm{HNMR}$ and ${ }^{13} \mathrm{CNMR}$ shifts of gemcitabine were determined as follows:

$$
\delta_{\text {calc }}\left(X_{i}\right)=\sigma(\mathrm{TMS})-\sigma\left(X_{i}\right),
$$

where $\sigma$ (TMS) and $\sigma\left(X_{i}\right)$ are the calculated isotropic magnetic shielding tensor of hydrogen and carbon of the reference (TMS) and gemcitabine, respectively. All of the calculations were performed in both gas and water solution phases.

\section{Results and discussion}

- Geometry: In the first section of computational analysis, geometrical structure was obtained (Figure 1$)$ at $6-311++\mathrm{G}(\mathrm{d}, \mathrm{p})$ basis set of DFT method. Vibrational frequencies were calculated in an optimized structure, and imaginary frequency was not observed.

In addition, an optimization process was performed in a solution phase using the Polarizable 
Continuum Model (PCM) [50] for aqueous solution, dimethyl sulfoxide (DMSO), chloroform and carbon tetrachloride $\left(\mathrm{CCl}_{4}\right)$ solution.

As Table 1 shows, there are significant differences between dihedral angles of gemcitabine in aqueous solution, compared to gas phase and other solvents. In addition, gemcitabine is more stable

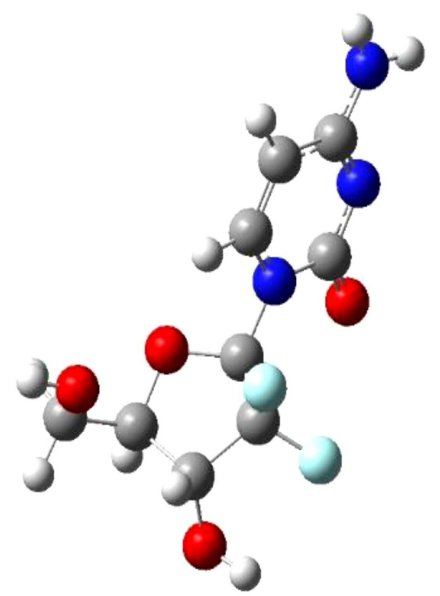

Figure 1. Optimized structures of gemcitabine calculated by B3LYP/6-311++G(d,p) method in gas phase. in the aqueous solution phase than others, showing $18.83 \mathrm{kcal} \mathrm{mol}^{-1}$ solvation energy. In fact, as will be shown, our impression is that the intermolecular hydrogen bonding with solvent molecules (Figure 2) would lead to special orientation of dihedral angles and greater stability.

Figure 3 shows the superposition of the lowest energy structure of gemcitabine in gas and aqueous solution phases. In aqueous media, the $\mathrm{OH}$ functional group at C9 is oriented toward the fluorine atom. This can be due to inter- or intra-molecular interactions that caused dihedral angles to become smaller than that in the gas phase. On the other hand, in the gas phase, space repulsion and space prevention can be the reason for the functional groups to stay away from each other.

More importantly in addition to the above theoretical prediction, H-H COSY NMR experiment (Figure 4) shows the weak correlation at solvent peak (4.75 ppm) and $\mathrm{OH}$ (at C9) peak (6.4 ppm). Therefore, it can be concluded that, in aqueous solution, gemcitabine is more stable than that in the gas phase and other solvents due to the performance of intermolecular hydrogen bonding, leading to special orientation of dihedral angles.

Table 1. The optimized ground state structural parameters of gemcitabine on DFT-B3LYP/6-311++G(d,p) level of theory in gas and solution phases.

\begin{tabular}{|c|c|c|c|c|c|}
\hline Parameters & Gas & Water & DMSO & $\mathrm{CCl}_{4}$ & Chloroform \\
\hline$\Delta E\left(\mathrm{kcal} \mathrm{mol}^{-1}\right)^{\mathrm{a}}$ & 18.83 & - & 0.63 & 11.30 & 6.28 \\
\hline \multicolumn{6}{|l|}{ Bond lengths $(\AA)$ : } \\
\hline$C_{7}-N_{1}$ & 1.44 & 1.45 & 1.45 & 1.45 & 1.45 \\
\hline$C_{10}-C_{11}$ & 1.52 & 1.52 & 1.52 & 1.52 & 1.52 \\
\hline$C_{7}-O_{7}$ & 1.42 & 1.42 & 1.42 & 1.42 & 1.42 \\
\hline$C_{8}-C_{9}$ & 1.55 & 1.55 & 1.55 & 1.55 & 1.55 \\
\hline$C_{8}-F$ & 1.38 & 1.37 & 1.38 & 1.38 & 1.38 \\
\hline$C_{4}-N_{4}$ & 1.36 & 1.35 & 1.35 & 1.35 & 1.35 \\
\hline \multicolumn{6}{|l|}{ Bond lengths $\left({ }^{\circ}\right)$ : } \\
\hline$O_{7}-C_{7}-C_{8}$ & 102.93 & 103.36 & 103.36 & 103.00 & 103.30 \\
\hline$O_{7}-C_{7}-N_{1}$ & 109.43 & 109.51 & 109.51 & 109.48 & 109.48 \\
\hline$C_{8}-C_{9}-C_{10}$ & 102.86 & 102.86 & 102.86 & 102.86 & 102.86 \\
\hline$C_{10}-C_{11}-O_{11}$ & 109.15 & 109.46 & 109.46 & 109.31 & 109.41 \\
\hline$N_{11}-C_{21}-O_{22}$ & 118.62 & 118.81 & 118.81 & 118.71 & 118.78 \\
\hline$N_{1}-C_{2}-N_{3}$ & 116.79 & 117.87 & 117.85 & 117.22 & 117.51 \\
\hline \multicolumn{6}{|l|}{ Dihedral angles: } \\
\hline$O_{7}-C_{7}-N_{1}-C_{2}$ & -132.18 & -135.73 & -135.59 & -133.07 & -133.76 \\
\hline$O_{11}-C_{11}-C_{10}-O_{7}$ & -68.43 & -65.88 & -65.95 & -67.73 & -66.96 \\
\hline$O_{9}-C_{9}-C_{8}-F$ & -22.83 & -12.74 & -12.83 & -19.61 & -13.64 \\
\hline
\end{tabular}

a Energy differences related to the aqueous solution. 


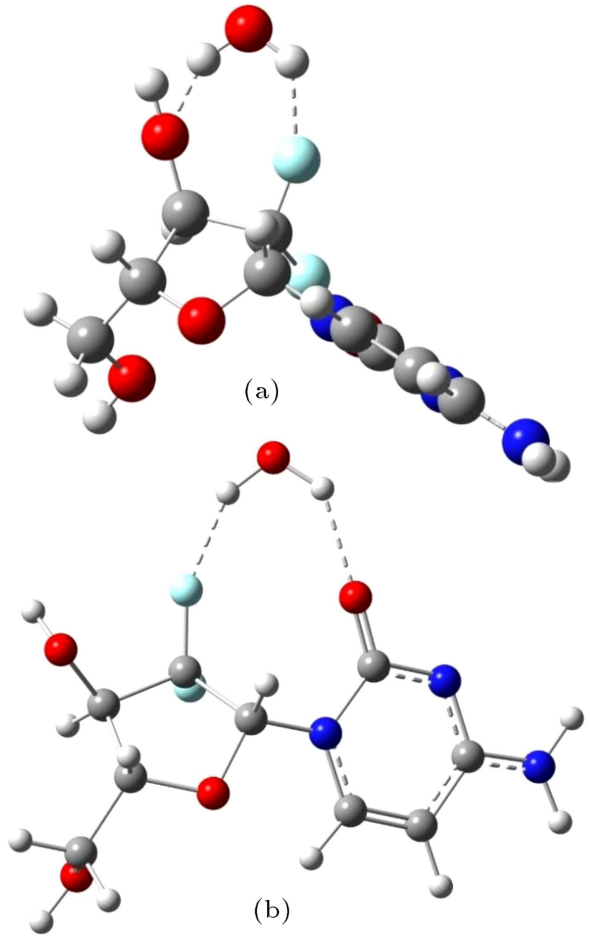

Figure 2. Special orientation of gemcitabine dihedral angles because of inter-molecular hydrogen bond interaction.

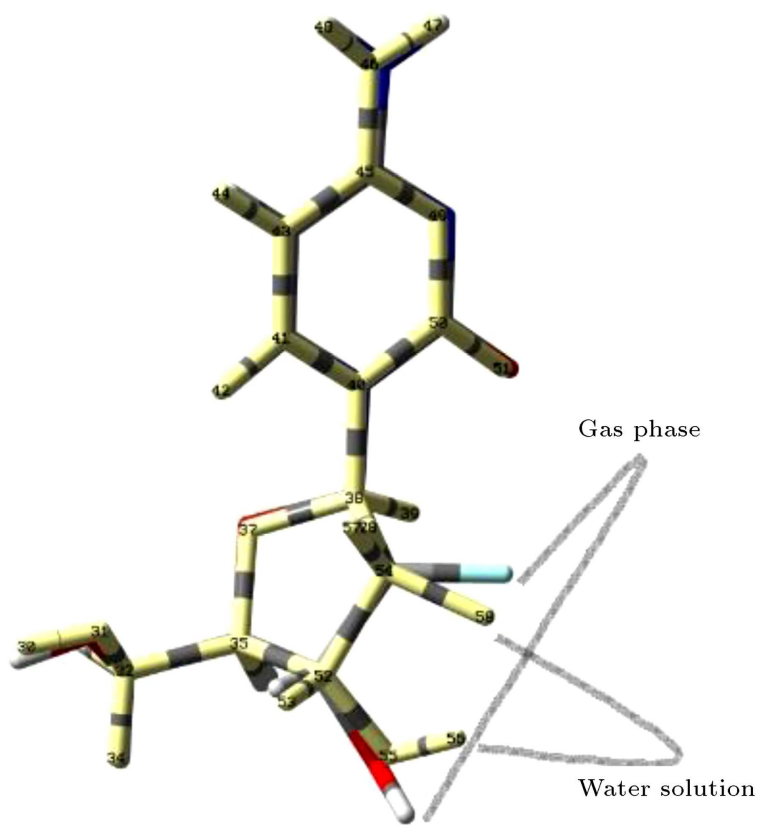

Figure 3. The superposition of the lowest energy structure of gemcitabine in gas and aqueous solution.

- NMR measurements: To interpret 3D structure and conformational study, we need to record a set of 1D- and 2D-NMR spectra such as homo- and heteronuclear correlation spectra (COSY, HMQC, and HMBC). H-H correlation spectroscopy (COSY) provides inter- and (rarely) intra-molecular correlations used frequently for molecular structure assignment and coupling constants measurement. Figure 4 shows the gemcitabine H-H COSY NMR experiment in $\mathrm{D}_{2} \mathrm{O}$ solvent. Figure 4 shows a weak correlation between solvent and sample signals. This correlation indicates intermolecular interaction which interprets the stability of G1conformer in aqueous media.

${ }^{1} \mathrm{~J}_{C-H}$ and ${ }^{2} \mathrm{~J}_{C-H}$ hetero-nuclear coupling constants were obtained from HMQC and HMBC NMR spectra and are shown in Figures 5 and 6, respectively.

- Computational analysis: A significant rotational energy barrier is the main key in conformational study. Energy scanning calculations around $\beta$ dihedral angle $\left(\mathrm{N}_{1}-\mathrm{C}_{6}-\mathrm{C}_{7}-\mathrm{O}_{7}\right)$ show significant energy barriers and, subsequently, stable conformers. A schematic diagram of energy as a function of $\beta$ is shown in Figure 7 . On the base of potential energy scanning diagram, the minimum points in PES are defined as available conformers, and it is concluded that these conformers exist, which are more stable than others are.

As Figure 7 shows, gemcitabine has three minimum energy points named G1, G2, and G3. The most stable conformer (G1) corresponds to the deepest point of PES, and $\beta$ angle is -60 degree. In fact, this conformer is more stable than other conformers due to carbonyl group orientation associated with both oxygen and fluorine in a sugar ring. In this condition, gemcitabine can minimize space repulsion energy and provide conditions for intramolecular interactions. Figure 8 shows the 3 dimensional structure of gemcitabine conformers in aqueous solution. Therefore, it can be concluded that space prevention, repulsion energy, and most importantly, inter- and intra-molecular interactions are persistent factors for gemcitabine conformers. Table 2 shows the energy differences and $\beta$ angle values for $\mathrm{G} 1$ to $\mathrm{G} 3$.

By applying GIAO method, ${ }^{1} \mathrm{H}$ and ${ }^{13} \mathrm{CNMR}$ chemical shifts were measured for G1 to G3 in gas and solution phases at PCM solvent model and were compared to TMS shift. Tables 3 and 4 show the experimental and theoretical comparison of hydrogen and carbon chemical shifts for G1 to G3 conformers, respectively.

Table 2. Energy differences of conformations of gemcitabine; $\beta$ is in degree.

\begin{tabular}{ccc}
\hline Conformer & Beta & $\boldsymbol{\Delta}^{\mathrm{a}}\left(\mathbf{k c a l} \mathbf{~ m o l}^{-\mathbf{1}}\right)$ \\
\hline G1 & -68.43 & - \\
G2 & 62.3 & 0.7 \\
G3 & 175.5 & 1.5 \\
\hline
\end{tabular}

${ }^{\mathrm{a}} \Delta=E_{\text {conf. }}-E_{G 1}$ 


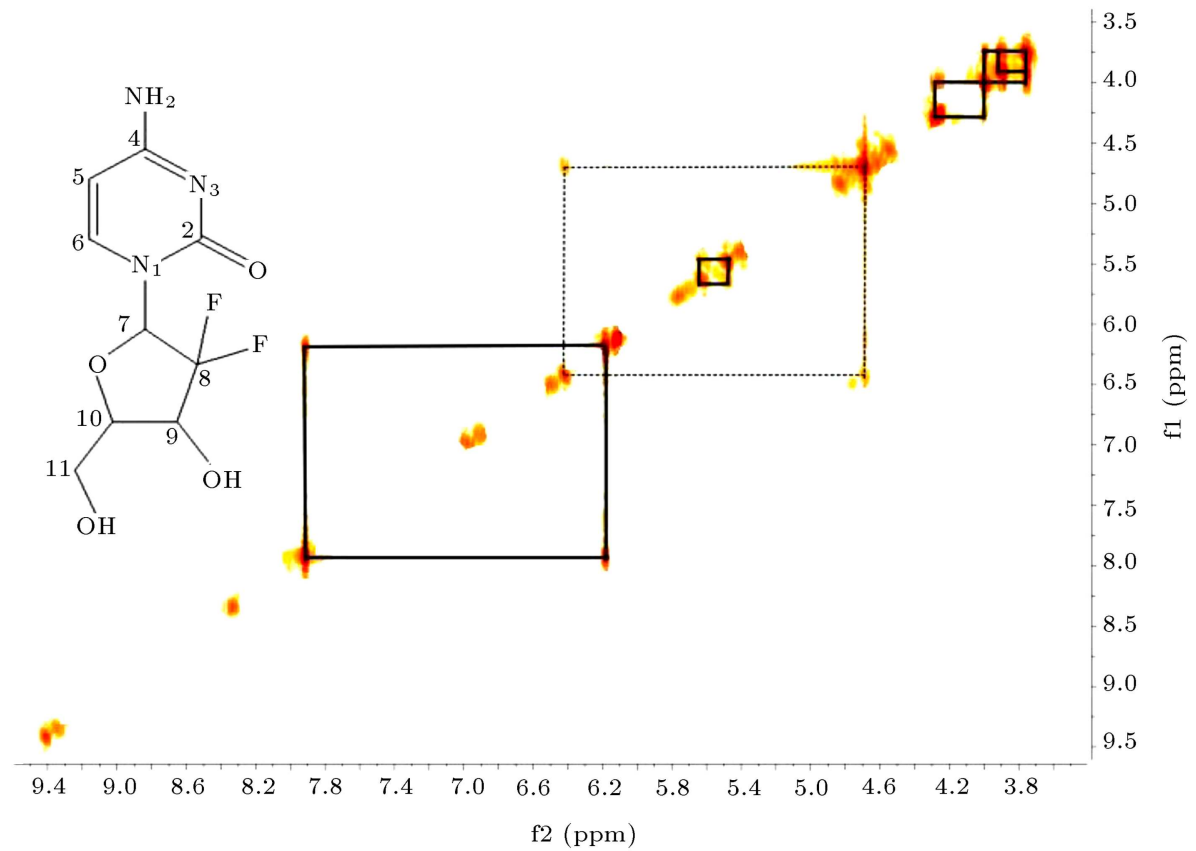

Figure 4. H-H COSY NMR spectra of Gemcitabine in aqueous solution.

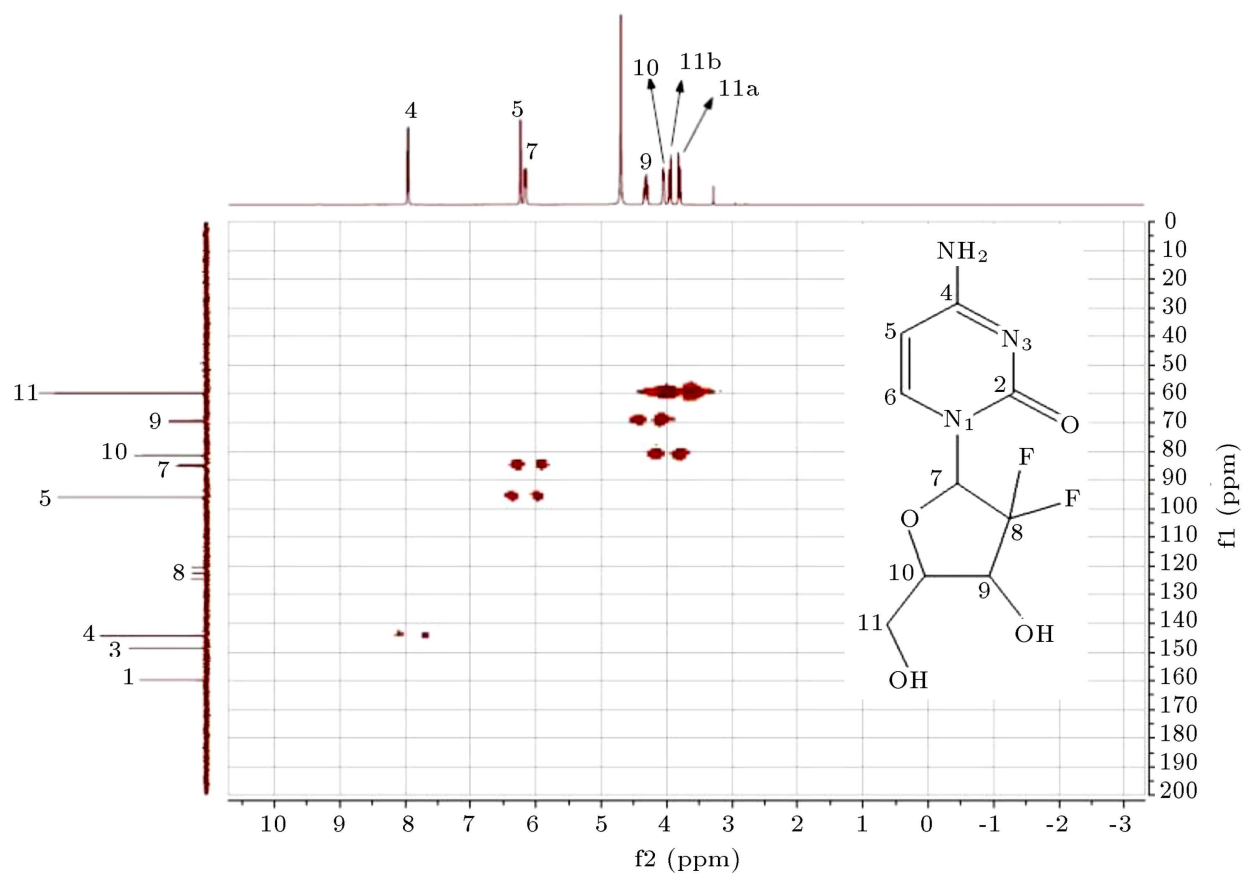

Figure 5. 2D-HMQC NMR spectra of gemcitabine in aqueous solution.

From energy differences and chemical shifts, it can be concluded that G1 conformer has a higher natural population, compared to other conformers; therefore, the calculated chemical shifts for G1 are closer to experimental results. Nevertheless, spinspin coupling constants are the NMR parameters related to structure parameters including dihedral angle. For this purpose, all ${ }^{n} \mathrm{~J}$-coupling constants $(n=1,2,3)$ of gemcitabine were experimentally obtained from 1-D and 2-D spectra in aqueous solution. In addition, spin-spin coupling constants were computed for G1 to G3 conformers using DFT/B3LYP/6-311 $++\mathrm{g}^{* *}$ method in a PCM solvent model. The results showed good agreement to the most stable conformer, G1 (Table 5).

In order to distinguish different conformers, the Karplus equations have been developed from ${ }^{n} \mathrm{~J}$ coupling constants $(n=1,2,3)$. For this purpose, 


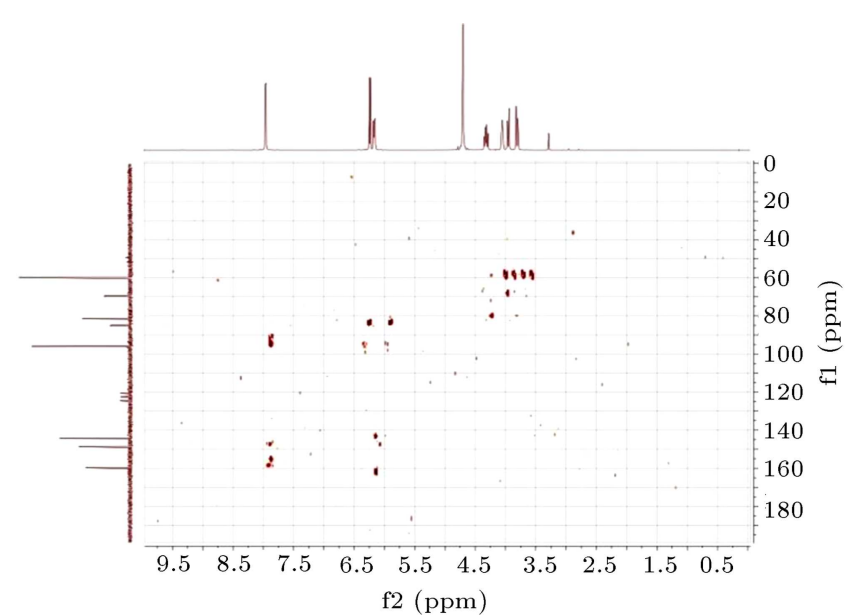

Figure 6. 2D-HMBC NMR spectra of gemcitabine in aqueous solution.

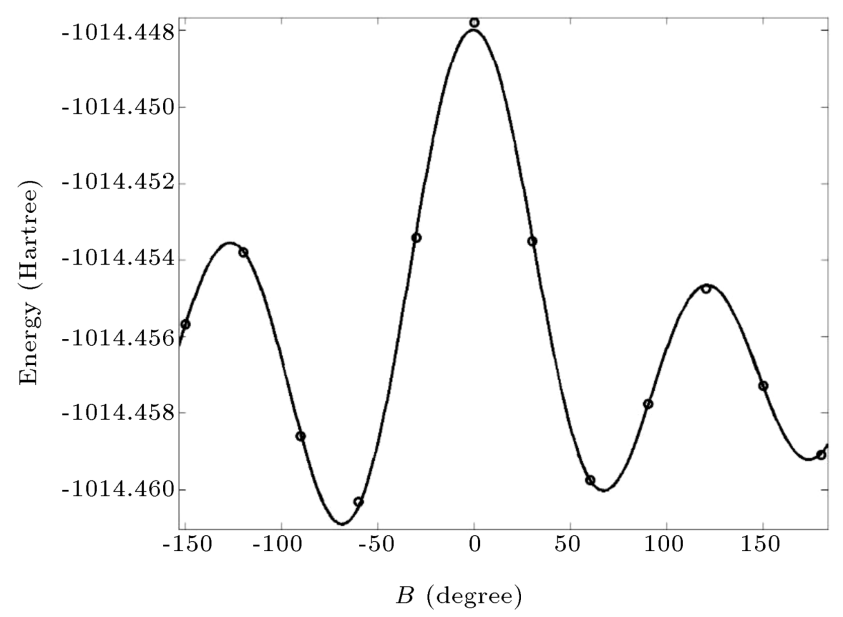

Figure 7. Diagram of Potential Energy Scanning (PES) of gemcitabine molecule, scanned around $\beta$ dihedral angle at DFT-B3LYP/6-311++G(d,p) level of theory.

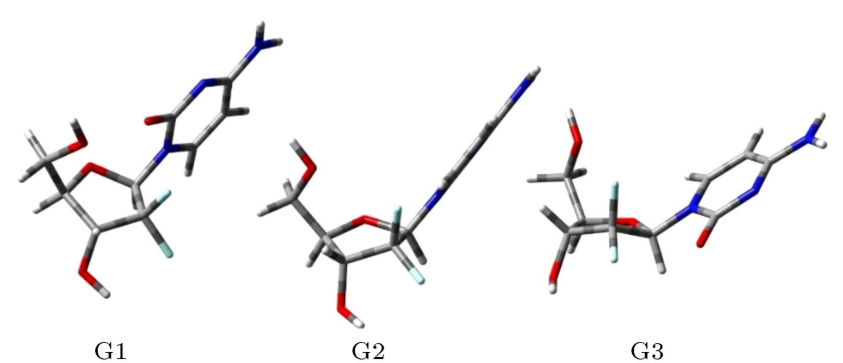

Figure 8. Molecular structure of gemcitabine's conformers in aqueous solution. G1 is the most stable of all other conformers due to its intramolecular interaction.

dihedral angle $(\beta)$ rotated from -180 to +150 with 30 increments, and 12 different modes were created. The spin-spin coupling constants were obtained and used to derive Karplus equation.

- One-bond spin-spin coupling constant: In order to derive the ${ }^{n} \mathrm{~J}$ Karplus equations $(n=1,2,3)$,
Table 3. Comparison of experimental (in $\mathrm{D}_{2} \mathrm{O}$ solvent) and theoretical $\left(6-311++\mathrm{G}^{* *}\right)^{1} \mathrm{H}$ chemical shifts (ppm).

\begin{tabular}{ccccc}
\hline & & \multicolumn{3}{c}{ Cal. } \\
\cline { 3 - 5 } H-atom & Exp. & G1 & G2 & G3 \\
\hline 5 & 7.96 & 7.81 & 7.36 & 7.34 \\
6 & 6.24 & 5.90 & 5.87 & 5.87 \\
7 & 6.17 & 6.69 & 5.44 & 5.52 \\
9 & 4.32 & 4.78 & 4.15 & 4.91 \\
10 & 4.05 & 4.19 & 4.02 & 4.44 \\
$11 \mathrm{a}$ & 3.81 & 4.18 & 4.11 & 4.09 \\
$11 \mathrm{~b}$ & 3.95 & 4.25 & 4.29 & 4.54 \\
\hline
\end{tabular}

Table 4. Comparison of experimental (in $\mathrm{D}_{2} \mathrm{O}$ solvent) and theoretical $\left(6-311++\mathrm{G}^{* *}\right){ }^{13} \mathrm{C}$ chemical shifts (ppm).

\begin{tabular}{ccccc}
\hline & & \multicolumn{3}{c}{ Cal. } \\
\cline { 3 - 5 } C-atom & Exp. & G1 & G2 & G3 \\
\hline 2 & 159.74 & 160.87 & 158.93 & 158.77 \\
4 & 148.62 & 151.11 & 150.69 & 150.53 \\
5 & 144.37 & 143.03 & 140.14 & 139.96 \\
6 & 96.00 & 92.65 & 90.85 & 90.91 \\
7 & 84.98 & 84.69 & 92.43 & 93.33 \\
8 & 122.49 & 129.43 & 129.24 & 128.81 \\
9 & 69.54 & 74.96 & 82.61 & 75.41 \\
10 & 81.49 & 86.35 & 86.64 & 84.05 \\
11 & 59.73 & 65.07 & 68.46 & 63.63 \\
\hline
\end{tabular}

Table 5. Experimental and calculated scalar coupling constants $(\mathrm{Hz})$ using DFT/B3LYP/6-311++g** method in a PCM solvent model for G1 conformer.

\begin{tabular}{lccc}
\hline & Exp. & Gas cal. & Water \\
\hline${ }^{1} J_{C 9-H 9}$ & 155.04 & 160.47 & 161.16 \\
${ }^{1} J_{C 10-H 10}$ & 185.04 & 156.70 & 156.24 \\
${ }^{1} J_{C 7-H 7}$ & 185.04 & 168.69 & 168.42 \\
${ }^{1} J_{C 5-H 5}$ & 196.55 & 152.07 & 157.52 \\
${ }^{1} J_{C 6-H 6}$ & 190.05 & 173.07 & 175.73 \\
${ }^{1} J_{C 11-H 11 a}$ & 215.06 & 143.23 & 146.29 \\
${ }^{2} J_{H 11 a-H 11 b}$ & -12.00 & -10.65 & -12.24 \\
${ }^{2} J_{F-H 9}$ & 11.50 & 10.73 & 12.05 \\
${ }^{3} J_{H 10-H 11}$ & 4.05 & 2.23 & 2.11 \\
${ }^{3} J_{H 10-H 9}$ & 8.50 & 2.75 & 4.8 \\
${ }^{3} J_{H 5-H 6}$ & 8.00 & 7.58 & 7.71 \\
\hline
\end{tabular}

the $J$-values of gemcitabine at different $\beta$ angles in gas and solution phases were calculated.

Orientation of $\mathrm{C}_{7}-\mathrm{H}_{7}$ bond toward carbonyl group leads to the exertion of maximum influence on ${ }^{1} \mathrm{~J}_{\mathrm{C} 7-\mathrm{H}_{7}}$ value. In addition, ${ }^{1} \mathrm{~J}_{\mathrm{C} 7-\mathrm{H}_{7}}$ is the only coupling constant directly related to $\beta$ angle. One of the major practical advantages of the angular 


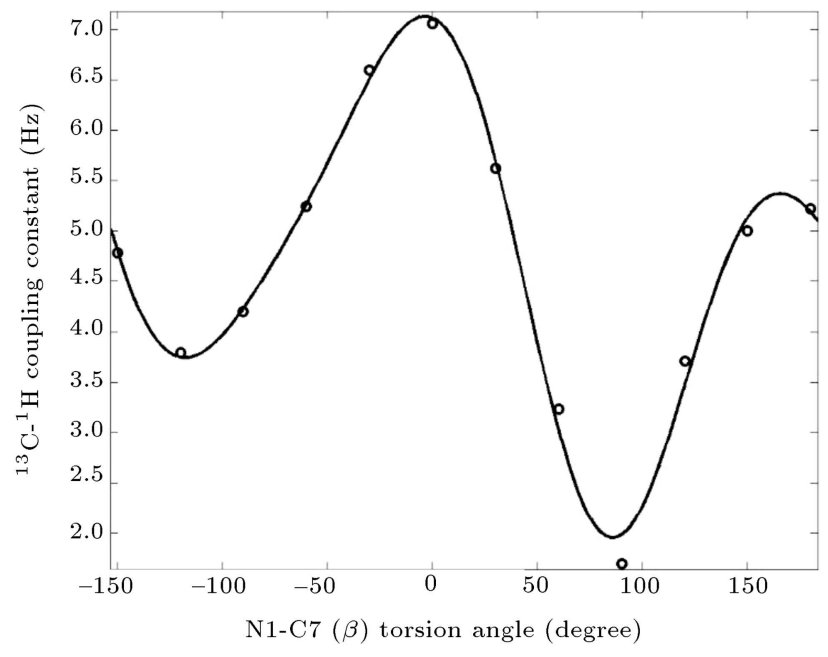

Figure 9. Plots of the dependencies of calculated ${ }^{2} \mathrm{~J}_{\mathrm{C} 8-\mathrm{H} 7}$ in gemcitabine at the $\beta$ angle.

dependences of ${ }^{1} \mathrm{~J}_{C-H}$ values is the possibility of determination of the torsional angles. Therefore, ${ }^{1} \mathrm{~J}_{\mathrm{C} 7-H 7}$ is chosen because, with the rotation of $\beta$ angles, $\mathrm{H}_{7}$ has the maximum effect. Eq. (1) shows ${ }^{1} \mathrm{~J}_{\mathrm{C} 7-\mathrm{H} 7}$ Karplus equation in the gas phase:

$$
\begin{aligned}
{ }^{1} J_{C 7-H 7}= & 265.2 \sin \left(6 * 10^{5}+2.5\right) \\
& +6.3 \sin (0.03 \beta-2.7) .
\end{aligned}
$$

- Geminal (two-bond) spin-spin coupling constant: The two-bond coupling constant has important effect in a biomolecular structural study. ${ }^{2} \mathrm{~J}_{\mathrm{C} 8-\mathrm{H} 7}$ Karplus equation as geminal coupling constant was obtained (Eq. (2)). Figure 9 shows the geminal coupling constants according to Eq. (2):

$$
\begin{aligned}
{ }^{2} J_{C 8-H 7}= & 5.69 \sin (0.003+2.04) \\
& +2.04 \sin (0.03-4.34) \\
& +0.43 \sin (0.05+0.37), \\
R^{2}= & 0.9904 .
\end{aligned}
$$

- Three-bond spin-spin coupling constant: The most important Karplus equation is homo- and hetero-nuclear ${ }^{3} \mathrm{JH}-\mathrm{X}$. Since there is not any ${ }^{3} \mathrm{JH}-\mathrm{H}$ for gemcitabine around $\mathrm{C}_{7}-\mathrm{N}_{6}$ bond, the three-bond ${ }^{13} \mathrm{C}^{1} \mathrm{H}$ coupling constant was measured to obtain ${ }^{3} \mathrm{~J}$ Karplus equation. Eq. (3) shows ${ }^{3} \mathrm{~J}_{\mathrm{C} 7-\mathrm{H} 8}$ Karplus equation in water solution. Figure 10 shows the three coupling constants according to Eq. (3).

$$
\begin{aligned}
{ }^{3} J_{H 7-C 8}= & 2.2 \sin (0.007 \beta+1.2) \\
& +0.68 \sin (0.07 \beta-0.4) \\
& +1.5 \sin (0.03 \beta-0.35), \\
R^{2}= & 0.9983 .
\end{aligned}
$$

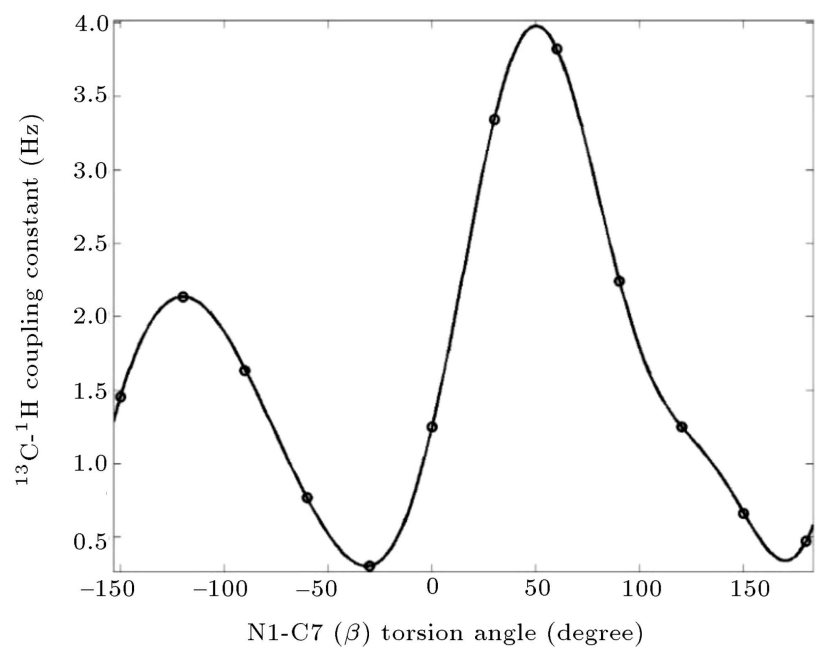

Figure 10. Plots of the dependencies of calculated ${ }^{3} \mathrm{~J}_{\mathrm{H} 7-\mathrm{C} 8}$ in gemcitabine at the $\beta$ angle.

\section{Conclusion}

This study considered conformational structure of gemcitabine by using 2D-NMR experiments and density functional theory. Molecular geometry, NMR parameters, and solvent effect were determined by using DFT/B3LYP/6-311++G(d,p) level of theory in gas and solution phases in a Polarizable Continuum Model (PCM). Based on these data, it can be concluded that gemcitabine is more stable in aqueous solution than other solvents are because of solvent-solute intermolecular interactions. In addition, solvent effect showed that stability of gemcitabine would be reduced from polar to non-polar solvents. In the gas phase, space repulsion results in instability compared to the solution phase as large as $18.83 \mathrm{kcal} / \mathrm{mol}$.

Experimental analysis and geometry calculations showed that inter- and intra-molecular interactions played key roles in particular orientation of dihedral and bond angles in aqueous solution than in gas phase. To verify this claim, a correlation of solvent and gemcitabine signals in $\mathrm{H}-\mathrm{H}$ COSY NMR experiment was shown. Conformational study using Potential Energy Scanning (PES) showed three stable conformers at a minimum point on PES. Spin-spin coupling constants were measured experimentally and theoretically to all conformers, and DFT calculations had good agreement with the 2D-NMR spectra. Based on the energy and NMR analysis, G1 conformer is more stable than others are.

\section{References}

1. Nguyen, H.V., Sallustrau, A., Balzarini, J., Bedford, M.R., Eden, J.C., Georgousi, N., Hodges, N.J., Kedge, J., Mehellou, Y., Tselepis, C. and Tucker, J.H.R. "Organometallic nucleoside analogues with ferrocenyl 
linker groups: Synthesis and cancer cell line studies", J. Med. Chem., 57, pp. 5817-5822 (2014).

2. Serpi, M., Ferrari, V., and Pertusati, F. "Nucleoside derived antibiotics to fight microbial drug resistance: New utilities for an established class of drugs", J. Med. Chem., 59, pp. 10343-10382 (2016).

3. Dracinsky, M. and Pohl, R. "Determination of the nucleic acid adducts structure at the nucleoside/nucleotide level by NMR spectroscopy", Chem. Res. Toxicol., 28, pp. 155-165 (2015).

4. Butora, G., Kenski, D.M., Cooper, A.J., Fu, W., Qi, N., Li, J.J., Flanagan, W.M., and Davies, I.W. "Nucleoside optimization for RNAi: A high throughput platform", J. Am. Chem. Soc., 133, pp. 16766-16769 (2011).

5. Zhang, W., Ntai, I., Bolla, M.L., Malcolmson, S.J., Kahne, D., Kelleher, N.L., and Walsh C.T. "Nine enzymes are required for assembly of the pacidamycin group of peptidyl nucleoside antibiotics", J. Am. Chem. Soc., 133, pp. 5240-5243 (2011).

6. Wu, R., Gong, W., Liu, T., Zhang, Y., and Cao, Z. "QM/MM molecular dynamics study of purine-specific nucleoside hydrolase", J. Phys. Chem. B., 116, pp. 1984-1991 (2012).

7. Slusarczyk, M., Lopez, M.H., Balzarini, J., Mason, M., Jiang, W.G., Blagden, S., Thompson, E., Ghazaly E., and McGuigan, C. "Application of proTide technology to gemcitabine: A successful approach to overcome the key cancer resistance mechanisms leads to a new agent (NUC-1031) in clinical development", J. Med. Chem., 57, pp. 1531-1542 (2014).

8. Fan, M., Liang, X., Li, Z., Wang, H., Yang, D., and Shi, B. "Chlorambucil gemcitabine conjugate nanomedicine for cancer therapy", J. Pharm. Sci., 79, pp. 20-26 (2015).

9. Moysan, E., Bastiat G., and Benoit, J.P. "Gemcitabine versus modified gemcitabine: A review of several promising chemical modifications", Mol. Pharmaceutics., 10, pp. 430-444 (2013).

10. Cavalcante, L.S. and Monteiro, G. "Gemcitabine: metabolism and molecular mechanisms of action, sensitivity and chemoresistance in pancreatic cancer", Eur. J. Pharmacol., 741, pp. 8-16 (2014).

11. Valle, J., Wasan, H., Palmer, D.H., Cunningham, D., Anthoney, A., Maraveyas, A., Madhusudan, S., Iveson, T., Hughes, S., Pereira, S. P., Roughton, M., and Bridgewater, J. "Cisplatin plus gemcitabine versus gemcitabine for biliary tract cancer", N. Eng.l. J. Med., 362, pp. 1273-81 (2010).

12. Jiang, X., Li, J., Zhang, R., Zhu, Y., and Shen, J. "An improved preparation process for gemcitabine", Organic Process Research \& Development, 12, pp. 888891 (2008).

13. Moysan, E., Bastiat, G., and Benoit, J.P. "Gemcitabine versus modified gemcitabine: A review of several promising chemical modifications", Mol. Pharmaceutics., 10, pp. 430-444 (2013).
14. Weiss, J.T., Dawson, J.C., Fraser, C., Rybski, W., Torres-Sanchez, C., Bradley, M., Patton E.E., Carragher, N.O., and Unciti-Broceta, A. "Development and bioorthogonal activation of palladium-labile prodrugs of gemcitabine", J. Med. Chem., 57, pp. 53955404 (2014).

15. Wang, Y., Fan, W., Dai, X., Katragadda, U., Mckinley, D., Teng, Q., and Tan, C. "Enhanced tumor delivery of gemcitabine via PEG-DSPE/TPGS mixed micelles", Mol. Pharmaceutics, 11, pp. 1140-1150 (2014).

16. Zhang, Z., Duan, Q., Zhao, H., Liu, T., Wu, H., Shen, Q., Wang, C., and Yin, T. "Gemcitabine treatment promotes pancreatic cancer stemness through the Nox/ROS/NF- $\kappa$ B/STAT3 signaling cascade", Cancer Letters, 382, pp. 53-63 (2016).

17. Brown, K., Wilson, A.W., and Linclau, B. "A linear synthesis of gemcitabine", Carbohydr. Res., 406, pp. 71-75 (2015).

18. Gowda, P.A.S., Polizzi, J.M., Eckert, K.A., and Spratt, T.E. "Incorporation of gemcitabine and cytarabine into DNA by DNA polymerase $\beta$ and ligase III/XRCC1", Biochemistry, 49, pp. 4833-4840 (2010).

19. Dasari, M., Acharya, A.P., Kim, D., Lee, S., Rhea, J., Molinaro, R., and Murthy, N. "H-gemcitabine: A new gemcitabine prodrug for treating cancer", Bioconjugate Chem., 24, pp. 4-8 (2013).

20. Kang, H., Kim, C., Kim, D., Song, J.H., Choi, M., Choi, K., Kang, M., Lee, K., Kim, H.S., Shin, J.S., Kim, J., Han, S.B., Lee, M.Y., Lee, S.U., Lee, C.K., Kim, M., Ko, H.J., Kuppeveld, F.J.M., and Cho, S. "Synergistic antiviral activity of gemcitabine and ribavirin against enteroviruses", Antiviral Res., 124, pp. 1-10 (2015).

21. Hricovíni, M. "Solution structure of heparin pentasaccharide: NMR and DFT analysis", J. Phys. Chem. B., 119, pp. 12397-12409 (2015).

22. Dorotíková, S. Plevová, K., Bučinský, L., Malček, M., Herich, P., Kucková, L., Bobenicčová, M., Šoralová, S., Kožİ̌sek, J., Fronc, M., Milata, V. and Dvoranova, D. "Conformational, spectroscopic, and molecular dynamics DFT study of precursors for new potential antibacterial fluoroquinolone drugs", J. Phys. Chem. A., 118, pp. 9540-9551 (2014).

23. Tosso, R.D., Zamora, M.A., Suvire, F.D., and Enriz, R.D. "Ab initio and DFT study of the conformational energy hypersurface of cyclic Gly-Gly-Gly", J. Phys. Chem. A., 113, pp. 10818-10825 (2009).

24. Vargas, R., Garza, J., Hay, B.P., and Dixon, D.A. "Conformational study of the alanine dipeptide at the MP2 and DFT Levels", J. Phys. Chem. A., 106, pp. 3213-3218 (2002).

25. Wang, L., Kefalidis, C.E., Roisnel, T., Sinbandhit, S., Maron, L., Carpentier, J.F., and Sarazin, Y. "Structure vs ${ }^{119} \mathrm{Sn}$ NMR chemical shift in threecoordinated tin (II) complexes: Experimental data and predictive DFT computations", Organometallics, 34, pp. 2139-2150 (2015). 
26. Blonski, P., Birczynski, A., Lalowicz, Z.T., Datka, J. and Lodziana, Z. "Structure of the hydroxyl groups and adsorbed D2O sites in the DX zeolite: DFT and experimental NMR data", J. Phys. Chem. C., 119, pp. 19548-19557 (2015).

27. Latosińska, N.J., Latosińska, M. and Tomczak, M.A. "Conformational stability and thermal pathways of relaxation in triclosan (antibacterial/excipient/contaminant) in solidstate: Combined spectroscopic (1H NMR) and computational (periodic DFT) study", J. Phys. Chem. A., 119, pp. 4864-4874 (2015).

28. Vijay, R., Mandal, A.B., and Baskar, G. " ${ }^{1} \mathrm{H}$ NMR spectroscopic investigations on the conformation of amphiphilic aromatic amino acid derivatives in solution: Effect of chemical architecture of amphiphiles and polarity of solvent medium", J. Phys. Chem. B., 114, pp. 13691-13702 (2010).

29. Shainyan, B.A., Kirpichenko, S.V., Shlykov, S.A., and Kleinpeter, E. "Structure and conformational properties of 1,3,3-trimethyl-1, 3-azasilinane: Gas electron diffraction, dynamic NMR, and theoretical study", $J$. Phys. Chem. A., 116, pp. 784-789 (2012).

30. Krishnan, R., Rakhi, A.M., and Gopidas, K.R. "Study of $\beta$-Cyclodextrin-Pyromellitic diimide complexation. conformational analysis of binary and ternary complex structures by induced circular dichroism and 2D NMR spectroscopies", J. Phys. Chem. C., 116, pp. 2500425014 (2012).

31. Sun, P., Xu, D., Mándi, A., Kurtán, A., Li, T., Schulz, B., and Zhang, W. "Structure, absolute configuration, and conformational study of 12- membered macrolides from the fungus dendrodochium sp. associated with the sea cucumber holothuria nobilis selenka", J. Org. Chem., 78, pp. 7030-7047 (2013).

32. Hong. M., Mishanina, T.V., and Cady, S.D. "Accurate measurement of methyl $13 \mathrm{C}$ chemical shifts by solidstate NMR for the determination of protein sidechain conformation: the influenza M2 transmembrane peptide as an example", J. Am. Chem. Soc., 131, pp. 7806-7816 (2009).

33. Trujillo, P.M., Nolis, P., and Parella, T. "CN-HMBC: A powerful NMR technique for the simultaneous detection of long-range $1 \mathrm{H}, 13 \mathrm{C}$ and $1 \mathrm{H}, 15 \mathrm{~N}$ connectivities", Org. Lett., 9, pp. 29-32 (2007).

34. Marek, R., Marek, J., Dostál, J., Táborska, E., Slavİk, J., and Dommisse, R. "Structural studies of benzophenanthridine alkaloid free bases by NMR spectroscopy", Magn. Reson. Chem., 40, pp. 147-152 (2002).

35. Shainyan, B.A., Suslova, E.N., and Kleinpeter, E. "Conformational analysis of 4,4-dimethyl-4-silathiane and its S-oxides", J. Phys. Org. Chem., 24, pp. 11881192 (2011).

36. Svetlana V., Kirpichenko, S.V., Kleinpeter, E., Ushakov, I.A., and Shainyan, B.A. "Conformational analysis of 3-methyl-3-silathiane and 3-fluoro3-methyl-3-Silathiane", J. Phys. Org. Chem., 24, pp. 320-326 (2011).
37. Pihlaja, K., Tähtinen, P., Klika, K.D., Jokela, T., Salakka, A. and Wähäla, K. "Experimental and DFT ${ }^{1} \mathrm{H}$ NMR study of conformational equilibria in trans4,7-dihydroxyisoflavan-4-ol and trans-Isoflavan-4-ol", J. Org. Chem., 68, pp. 6864-6869 (2003).

38. Chashmniam, S. and Tafazzoli, M. "NMR investigation and theoretical calculations of the solvent effect on the Conformation of valsartan", J. Mol. Struct., 1148, pp. 73-80 (2017).

39. Chashmniam, S. and Tafazzoli, M. "Conformation of repaglinide: A solvent dependent structure", J. Mol. Struct., 1143, pp. 388-396 (2017).

40. Bagno, A., Casella, G., Ferrante, F. and Saielli, G. "A DFT study of the vicinal ${ }^{3} \mathrm{~J}\left({ }^{119} \mathrm{Sn},{ }^{13} \mathrm{C}\right)$ and ${ }^{3} \mathrm{~J}\left({ }^{119} \mathrm{Sn},{ }^{1} \mathrm{H}\right)$ coupling constants in trimethyl- and chlorodimethylstannyl propanoates", J. Organomet. Chem., 724, pp. 139-146 (2013).

41. Dewberry, C.T., Huff, A.K., Mackenzie, R.B., and Leopold, K.R. "Microwave spectrum, van der Waals bond length, and 131Xe quadrupole coupling constant of Xe-SO3", J. Mol. Spectrosc., 304, pp. 43-46 (2014).

42. Shahkhatuni, A.A., Shahkhatuni, A.G., Minasyan, N.S., Panosyan, H.A., and Sahakyan, A.B. "Revealing the specific solute-solvent interactions via the measurements of the NMR spin-spin coupling constants", $J$. Mol. Struct., 1083, pp. 175-178 (2015).

43. Schuquel, I.T.A., Ducati, L.C., Tormena, C.F., Freitas, M.P., Kowalewski, D.G., and Rittner, R. ${ }^{~}{ }^{13} \mathrm{C}$ NMR: ${ }^{n} \mathrm{~J}_{C H}$ and ${ }^{1} \mathrm{~J}_{C C}$ scalar spin-spin coupling constants (SSCCs) for some 3-monosubstituted 2methylpropenes", J. Mol. Struct., 1068, pp. 170-175 (2014).

44. Coxon, B. "A Karplus equation for ${ }_{3} \mathrm{JHCCN}$ in amino sugar derivatives", Carbohydr. Res., 342, pp. 10441054 (2007).

45. Ghiasi, M., Oskouie, A.A., and Saeidian, H. "Dynamic stereochemistry of topiramate (anticonvulsant drug) in solution: Theoretical approaches and experimental validation", Carbohydr. Res., 348, pp. 47-54 (2012).

46. Frisch, M.J., Trucks, G.W., Schlegel, H.B., et al., Gaussian 09, revision D.01; Gaussian, Inc.: Wallingford, CT (2009).

47. Becke, A.D. "A new mixing of Hartree-Fock and local density-functional theories", J. Chem. Phys., 98, pp. 1372-1377 (1993).

48. Lee, C., Yang, W., and Parr, R.G. "Development of the Colle-Salvetti correlation-energy formula into a functional of the electron density", Phys. Rev. B., 37, pp. 785-789 (1988).

49. Asiri, A.M., Karabacak, M., Kurt, M., and Alamry, K.A. "Synthesis, molecular conformation, vibrational and electronic transition, isometric chemical shift, polarizability and hyperpolarizability analysis of 3(4-methoxy-phenyl)-2-(4-nitro-phenyl) acrylonitrile: A combined experimental and theoretical analysis", Spectrochimica Acta Part A., 82, pp. 444-455 (2011). 
50. Tomasi, J., Mennucci, B., and Cammi, R. "Quantum mechanical continuum solvation models", Chem. Rev., 105, pp. 2999-3093 (2005).

\section{Biographies}

Saeed Chashmniam was born in 1989 in Eqlid, Iran. He received his BSc degree in Applied Chemistry from the University of Maragheh in 2012 and completed his MSc degree in the field of Physical Chemistry at the Sharif University of Technology in 2014. Now, he is a PhD Candidate in Sharif University of Technology on the topic of conformation of drug compounds using advanced NMR and DFT calculation methods under the supervision of Professor Mohsen Tafazzoli.

Mohsen Tafazzoli obtained his BSc degree from Shahid Beheshti University of Iran in 1981. In addition, he received his $\mathrm{PhD}$ degree in University of California, Davis in 1992 and, then, joined the Chemistry Department of the Sharif University of Technology. His research field involves the dynamic NMR spectroscopy (DNMR), structure elucidation of saccharides, ${ }^{1} \mathrm{H} /{ }^{13} \mathrm{C}$ chemical shifts in the gas phase, calculation of chemical shielding, and nuclear quadrupole coupling constants (NQCC). 